\title{
Decision-Making Styles and Subjective Performance Evaluation of Decision-Making Quality among Hospital Nurses
}

\author{
Lukáš Pitel \\ Institute of Experimental Psychology \\ Center of Social and Psychological Sciences, \\ Slovak Academy of Sciences
}

\author{
Andrej Mentel \\ Institute of Social Anthropology \\ Faculty of Social and Economic Sciences, \\ Comenius University
}

\begin{abstract}
The Melbourne Decision Making Questionnaire (MDMQ) is a widely used measure of decisionmaking styles (adaptive: vigilance; and maladaptive: hypervigilance, buck passing, and procrastination), but there is little evidence regarding its predictive ability in professional settings. The aim of the study was to assess the association between MDMQ dimensions and subjective performance evaluation of decision-making quality (SPEDM) among hospital nurses $(N=109)$. We also assessed whether MDMQ can predict variance in SPEDM when controlled for affective traits (neuroticism - BFI; and self-esteem - RSES), social desirability (MC-SDS10), and length of practice. Self-rated SPEDM was positively associated with vigilance, and negatively associated with maladaptive decision-making styles. Supervisor-rated SPEDM was unrelated to decision-making styles. Social desirability slightly affected the relationships between self-rated SPEDM and decision-making styles. Despite several limitations, the results cast doubt regarding the ability of the MDMQ to predict decision-making quality.
\end{abstract}

Key words: decision-making styles, subjective performance evaluation, self-ratings, supervisor ratings, Melbourne Decision Making Questionnaire, social desirability, self-esteem, neuroticism

\section{Introduction}

Apart from aspects of the decision task and decision situation, decision outcomes might also be influenced by the characteristics of the decision-maker (Scott \& Bruce, 1995). In recent decades, several researchers have claimed to find individual differences in decision-making

Acknowledgements: This work was supported by the Slovak Research and Development Agency under contract No. APVV-0361-12.

Conflicts of interest: None declared.

Correspondence concerning this article should be addressed to Lukáš Pitel, Institute of Experimental Psychology, Center of Social and Psychological Sciences, Slovak Academy of Sciences, Dúbravská cesta 9, 84104 Bratislava, Slovak Republic, E-mail: lukas.pitel@savba.sk

Received December 9, 2016 styles (DM styles), i.e., "a tendency to approach the decision situation in similar ways across time and situation" (Wood \& Highhouse, 2014). Multiple categorizations of DM styles have been proposed based on various theoretical approaches (Leykin \& DeRubeis, 2010; Scott \& Bruce, 1995). The four-dimension Melbourne Decision Making Questionnaire (MDMQ) (Mann, Burnett, Radford, \& Ford, 1997), one of the most widely used instruments for measuring DM styles, is based on the conflict theory of decision-making (DM) by Janis and Mann (1977, in Mann et al., 1997). According to the conflict theory, high quality DM is impaired by stress engendered by decisional conflict. This stress stems from concerns about potential negative consequences of a decision gone wrong: a concern about personal, material or social losses, and a concern over loss of reputation and self-esteem. If a difficult, potentially threatening situation requiring a decision gen- 
erates stress, different patterns of coping can be applied.

In their revised model based on the conflict theory, Mann et al. (1997) identified four major coping patterns:

- Vigilance - considering the relevant information carefully before making a decision. In the MDMQ, for example, vigilance is measured by the item: "I try to be clear about my objectives before choosing". Vigilance is associated with a moderate level of stress;

- Hypervigilance - making decisions under severe emotional stress, searching frantically for a way out of dilemmas (e.g., "The possibility that some small thing might go wrong causes me to swing abruptly in my preference");

- Defensive avoidance, manifested in buckpassing - escaping conflict by shifting responsibility to someone else (e.g., "I prefer to leave decisions to others"), associated with high stress;

- Defensive avoidance, manifested in procrastination - escaping conflict by putting off making decisions (e.g., "I delay making decisions until it is too late"), associated with high stress.

Vigilance is usually considered an adaptive coping pattern, and the remaining three patterns as maladaptive (Gorodetzky, Sahakian, Robbins, \& Ersche, 2011; Kamhalová, Halama, \& Gurňáková, 2013). However, according to Bouckenooghe, Vanderheyden, Mestdagh, and van Laethem (2007), hypervigilance, buck-passing and procrastination can be considered adaptive as well, under certain circumstances. These four coping patterns have also been referred to as DM styles or decision/decisional styles in subsequent studies or reviews (Phillips \& Reddie, 2007; Deniz, 2011; Di Fabio \& Palazzeschi, 2012).

Conflict theory, operationalized by the MDMQ, has generated a considerable amount of research. For example, DM styles, as measured by the MDMQ, have been found to be related to attachment styles (Deniz, 2011), Big
Five personality traits (Halama \& Gurňáková, 2014), the need for cognition, and the need for closure (Bouckenooghe et al., 2007). However, a substantial part of the studies using the MDMQ were carried out on university students rather than other populations or professional groups.

According to Mann et al. (1997), stress engendered by decisional conflict, when it is coped with via maladaptive patterns, is a major determinant of failure to achieve high-quality decision making. However, only a few studies have compared the (self-reported) MDMQ dimensions to non-self-reported measures. Di Fabio and Palazzeschi (2012) found that fluid intelligence was related slightly positively to vigilance, and slightly negatively to maladaptive DM styles. Mann, Beswick, Allouache, and Ivey (1989) found a positive correlation between the pre-workshop FDMQ procrastination scale score (which intact became the MDMQ procrastination scale) and the number of days taken to return post-workshop evaluations. However, a postponed completion and return of evaluations is not necessarily an indicator of decision-making procrastination. In any case, surprisingly little is known about how the MDMQ dimensions are related to non-self-reported, external criteria of decision-making quality such as supervisor ratings.

\section{Decision-Making Styles and Other Personality Characteristics Explaining Decision Outcomes}

As mentioned above, considerable research suggests that relationships exist between DM styles and other, more fundamental, personality traits (Deniz, 2011; Halama \& Gurňáková, 2014). Additionally, both personality traits and DM styles - measured by instruments other than the MDMQ - were found to be associated with some indicators of DM performance. According to Dewberry, Juanchich, and Narendran 
(2013), who used the Decision Style Questionnaire (Leykin \& DeRubeis, 2010), both DM styles and Big Five traits jointly - and independently - accounted for a substantial amount of variance in self-reported everyday DM competence. Wood and Highhouse (2014) found that DM styles, measured by the General Decisionmaking Scale (GDMS) by Scott and Bruce (1995), jointly predicted self-rated (but not peer-rated) DM quality above that accounted for by the Big Five personality traits. This lack of associations between most of the measured DM styles and peer-rated DM quality above that accounted for by the Big Five personality traits seems striking, because DM styles bear a stronger theoretical tie to decision outcomes than the more global Big Five traits.

To our knowledge, there are currently no similar studies that compare the predictive ability of MDMQ-based DM styles with other, more fundamental, personality traits in relation to either DM performance or to subjective performance evaluation of one's DM quality (SPEDM). In particular, social desirability, neuroticism and self-esteem could theoretically affect both MDMQ-based DM styles and SPEDM: social desirability due to the supposed general tendency of certain individuals to respond in a favorable manner pertaining to operationalizations of diverse psycholigcal determinants and outcomes; and neuroticism and self-esteem due to their connection to DM styles - particularly maladaptive styles - according to conflict theory. Below we provide the rationale for this assumption in regards to each of these three personality characteristics.

\section{Social Desirability}

Self-report of one's own perfomance, personality traits, behavioral and coping patterns, and other psychological constructs may be biased due to a number of factors (Spector, 2006). For example, responses may be distorted by social desirability, i.e., the tendency to answer questions in a manner viewed favorably by others (Ganster, Hennessey, \& Luthans, 1983; Chen, Dai, Spector, \& Jex, 1997; King \& Bruner, 2000). When two or more variables from data obtained by self-report are compared, social desirability might inflate the observed correlations as a confounder. When self-ratings are compared with ratings by others, or with more objective performance criteria, social desirability might attenuate the actual relationships as a supressor. However, reviews of the literature indicate that social desirability has mostly little to no effect on the mutual relationships between various personality traits (Moorman \& Podsakoff, 1992), or between self-reported personality characterstics and job-performance indicators (Ones, Viswesvaran, \& Reiss, 1996). Still, the role of social desirability in self-reports of DM styles remains largely unexplored. Engkvist (2010) found a weak but statistically significant association of social desirability with vigilance, negative association with hypervigilance and procrastination of a similar strength, and no association with buck-passing. It can be assumed that respondents with high social desirability indeed tend to overreport their adaptive decision-making patterns and underreport maladaptive patterns.

\section{Neuroticism}

Individuals with high neuroticism (compared to low) perceive their events as more stressful and become more emotionally reactive as their appraisals become more severe (Gunthert, Cohen, \& Armeli, 1999). According to conflict theory, a preference for adaptive or maladaptive DM styles is associated with the level of perceived stress of the decision-maker. Hence, individuals with high neuroticism should be prone to less frequent use of the adaptive vigilant DM style and more frequent use of maladaptive DM styles. 
Several studies (Deniz, 2011; Di Fabio, 2006; Halama \& Gurňáková, 2014) indeed found an association between neuroticism and DM styles in these directions, although their study designs do not allow for causal inferences.

\section{Self-Esteem}

As affective variables co-determine decisionmaking processes in humans (Loewenstein \& Lerner, 2003), it can be assumed that the way the decision-maker feels about himself or herself may account for a considerable portion of individual differences in SPEDM.

Additionally, according to Mann et al. (1997), a concern over loss of self-esteem if the decision goes wrong is one of the major sources of psychological stress arising from decisional conflict. Leary and Downs (1995) suggest that concerns with social acceptance is more salient for individuals with lower self-esteem. This could indicate that those individuals also experience more stress due to their concerns about severe social losses if their decisions go wrong. The enhanced stress level might result in their higher preference for maladaptive DM styles and worse decision outcomes. Janis and Mann (1977; in Mann et al., 1997) view procrastination and buck-passing as maladaptive coping mechanisms for handling conflicts in decision-making: people delay or pass the buck in regard to thinking about conflicting alternatives in order to avoid stressful confrontations. Evidence suggests that low selfesteem is indeed associated with maladaptive decision-making. This holds for self-reports by adult workers from various professional backgrounds (Phillips \& Reddie, 2007) as well as college students (Effert \& Ferrari, 1989; Di Fabio, 2006; Ferrari, 1994). In our study, we extend the research to a professional group of nurses and also evaluate the predictive ability of self-esteem in regards to supervisor-rated SPE of their DM.

\section{Effective Decision-Making and its Measure- ment in the Professional Context of Nursing}

In the course of their work, it is not unusual for nurses to be exposed to unstructured situations under time pressure, when their fast and efficient decision-making is of great importance. Low-quality decision-making of healthcare professionals, including hospital nurses, may have serious consequences, including human and economic harm (Halama \& Gurňáková, 2014). Moreover, in recent decades, nurses have been increasingly cast in the role of active decision-makers in health care by policy makers and other members of health care teams (Thompson, 2004). This holds particularly true for Western European and AngloSaxon countries. However, recent reforms of health care policies in some Central and Eastern European countries (CEEC) have also created more space for strengthening the competencies of nurses in clinical DM. For example, in Slovakia, where the data for our study were collected, the competences of nurses were defined by law in 2005 for the first time - as a heath care provider and a member of a team - not a physician's subordinate. Educational requirements for nurses have also increased (Body of laws of the Slovak Republic, 2015a).

Despite these legislative changes, it can still be argued that in practice Slovak hospital nurses still remain de facto subordinates of physicians, due to the prevailing perceived "traditional roles" for nurses and physicians. Moreover, according to an additional - and equally valid legislative specification of medical practice, the physician is the one who determinates the medical procedure. Nurses are supposed to treat the patient accordingly (Body of laws of the Slovak Republic, 2015b). This is also the reason why physicians, along with nurse managers, were included in our study as rating supervisors of regular nurses. 
The extent to which nurses are involved in medical DM varies by work environment, perceptions of their clinical role and operational autonomy and the degree to which they see themselves as active and influential decisionmakers (Thompson, 2004). In many workplaces, the DM quality of nurses may be of essential importance, but it is rather difficult to find an "objective" indicator of their overall DM performance. For now, we will rely on the self-reported and supervisor-rated SPEDM of the nurses. These measurement methods are certainly not without limitations and potential bias (Conway \& Lance, 2010). Nevertheless, both self-rating (ibid.) and supervisor-rating of performance have generally been shown to provide a rather valid source of information on effectiveness (Hoffman, Nathan, \& Holden, 1991; Nathan \& Alexander, 1988).

\section{Aims of the Study}

In summary, the authors of the MDMQ scale imply an association of maladaptive DM patterns (in situations under high stress) with impaired DM quality (Mann et al., 1997). However, despite the wide use of the MDMQ scale, its relationship to indicators of DM quality other than self-report has been largely unexplored, particularly in a professional context. There is also little to no research evidence on the role of social desirability in responding to the MDMQ as a self-report measure. Moreover, despite the strong theoretical ties between neuroticism, selfesteem and MDMQ-based DM styles, which one of them is better at predicting DM quality remains unknown. Since DM styles are conceptually more proximate to DM than the more general traits of neuroticism and self-esteem, it can be hypothesized that they are also better predictors of SPEDM. However, some of the research findings by Wood and Highhouse (2014) with the GDMS scale cast doubt on this assumption. Noticeably, the incremental predic- tion of DM quality over the more general personality traits depended on the source of the ratings of DM quality. Based on the reported evidence (or lack thereof), our study aims to respond to the following research questions:

1 . Is there any relationship between self-reported DM styles of nurses and their SPEDM?

2. Does social desirability affect the relationship between DM styles and SPEDM?

3. Can DM styles predict SPEDM beyond other well-established personality measures that are related to the conflict theory approach (i.e., neuroticism and self-esteem) and situational variables (i.e., age and length of practice)?

4. Are the relationships explored in research questions 1-3 different for self-rated and supervisor-rated SPEDM?

\section{Methods}

\section{Sample and Procedure}

Data were collected in June 2014 among nurses from the Children's University Hospital in Bratislava, Slovakia. Five clinics with relatively the most demanding requirements of the nursing staff regarding their decision-making were chosen: Anaesthesiology and Intensive Care, Oncology and Haematology, Neurology, Pathological Neonatology, and Surgery. The authorities of the Anaesthesiology and Intensive Care clinic refused to participate. After approval of the survey by the local Ethics Committee, the questionnaires were distributed by the nurse managers of the remaining departments. The questionnaires were completed on a voluntary basis. Apart from decision-making and personal scales, the questionnaire also included a question on the nurse's year and the month of birth.

Nurse managers assigned a code number to each regular nurse from their own department. The month and year of birth of each nurse was 
added next to her code number (the nurse managers already had this information due to their administrative tasks). Afterwards, the supervisors rated their suburdinate nurses' SPEDM on the rating scales, marking the identities of the nurses with the code numbers. Subsequently, the column with names of the nurses on the coding sheet was discarded by the raters. Thus the author was able to match the self-report questionnaires of most regular nurses with their supervisors' ratings without knowing or revealing the identities of the nurses.

All raters still served the shifts with their regular nurses; thus they were in daily contact with them during their practice. The questionnaires of the regular nurses and the rating scales and coding sheets of the supervisors were returned on a specified date, each case in a separate sealed envelope. Vouchers worth 5 or 10 euro, exchangeable for goods in various chain stores, were provided as incentives for the participants.

The response rate was $94.4 \%$. Of the 117 regular nurses who returned the questionnaires, three were excluded because they were not rated by their supervisors, or because their questionnaires could not be matched with the supervisors' ratings. Data were inspected for unusually homogeneous responses. The data of five responders were discarded due to a suspicious response behavior indicating sloppy responding, i.e., a sudden onset of marking the same value in a row in the last ten items or more of the MDMQ scale (compare Wood \& Highhouse, 2014). The final analyses were performed on 109 regular nurses (107 females; mean age 38.7 years; $S D \pm 8.8$ years; mean length of practice at the current department $10.3 \pm 7.2$ years; previous health care practice outside the department 7.2 \pm 9.1 years).

\section{Measures}

Sociodemographic and contextual measures originally included gender, age, years of prac- tice spent at the current department, and previous practice in other healthcare facilities.

An instrument used previously by Kamhalová et al. (2013) and Halama and Gurňáková (2014) was deployed as the measure of self-rated-and supervisor-rated SPEDM. Self-rated SPEDM was measured by the question "To what extent are you convinced that you make the correct decisions at work?" (Literal translation: "To what extent are you convinced that you decide in the right way at work?") Analogically, the supervisor-rated SPEDM question was formulated as follows: "To what extent are you convinced that this nurse makes the correct decisions at work?" The responses were to be marked on a 100-millimeter visual analogue scale, under which three verbal answers were put in order to clarify the scale direction ("absolutely not - moderately absolutely"). The score was calculated as the distance in millimeters of the mark from the left edge of the scale, with a higher score indicating a higher SPEDM.

Decision-making styles were measured by the Melbourne Decision Making Questionnaire (MDMQ) (Mann et al., 1997), a 22-item self-report inventory designed to measure the tendencies to use the four major DM styles ("coping patterns") identified in the conflict theory of decision-making: vigilance, hypervigilance, buck-passing and procrastination. Sample items for each of the DM styles are provided in the first part of the Introduction. At each item, participants indicated the appropriate response to a statement, choosing from three possible options on a Likert-type scale: Items scored with 'True for me' were allocated 2 points, 'Sometimes true' were allocated 1 point, and 'Not true for me' were allocated 0 points. The instruction for the questionnaire was partly contextualized: "Please mark on a 3-point scale to what extent these statements reflect your behavior in a difficult situation when it is necessary to make an important decision". 
Social desirability was measured by a short form of the Marlow-Crowne Social Desirability Scale MC10(1) by Strahan and Gerbasi (1972), also known as the SDS X1. It consisted of 10 items from the original 33-item scale (Crowne \& Marlowe, 1960), with a dichotomous "true false" scale.

Self-esteem was measured by the Rosenberg Self-Esteem Scale (RSES) (Rosenberg, 1965), which consists of 10 items on a 4-point scale ranging from 1 ("strongly disagree") to 4 ("strongly agree").

Neuroticism was measured by the Neuroticism sub-scale from the Big Five Inventory, consisting of 8 items on a 5-point scale ranging from 1 ("disagree strongly") to 5 ("agree strongly”) (John, Naumann, \& Soto, 2008).

\section{Statistical Analyses and Results}

For multicollinearity detection, the variance inflation factor (VIF) was calculated using the function vif() from the R package $u s d m$ (Babak, 2015). Multicollinearities between the age-relevant predictors were found (VIF $>4)$. After excluding age and practice outside the current department, no more multicollinearities were identified in the set of predictors.

In order to assess internal consistency, Cronbach's Alpha was calculated for all measures with multiple items. Average scores of selfrated and supervisor-rated SPEDM were calculated for each department and for the whole sample (Table 1) as well as a Pearson correlation matrix of all measures (Table 2).

Self-rated SPEDM was positively associated with vigilance, and negatively associated with maladaptive styles. Supervisor-rated SPEDM was significantly associated only with years of practice at the department.

Neuroticism was positively related with maladaptive DM styles. Regarding self-esteem, negative associations with maladaptive DM styles of a similar magnitude were found.

Social desirability was positively associated with self-rated SPEDM and vigilance, unrelated to supervisor-rated SPEDM, and negatively associated with hypervigilance and procrastination. Controlling for social desirability had only a negligible impact on the strength of the

Table 1 Sample characteristics: Number of regular nurses, and their self-rated and supervisor-rated subjective performance evaluations of decision making quality (SPEDM) by department

\begin{tabular}{llccc}
\hline Clinic & Clinic departments & $\begin{array}{c}\text { Number of } \\
\text { regular } \\
\text { nurses }\end{array}$ & $\begin{array}{c}\text { Self-rated } \\
\text { SPEDM } \\
\text { (Mean and } \\
\text { SD) }\end{array}$ & $\begin{array}{c}\text { Supervisor-rated } \\
\text { SPEDM } \\
\text { (Mean and SD) }\end{array}$ \\
\hline $\begin{array}{l}\text { Oncology and } \\
\text { Haematology }\end{array}$ & Oncology & 26 & $86.4(10.1)$ & $93.0(9.8)$ \\
Beurology & Haematology & 14 & $78.8(17.9)$ & $89.0(14.1)$ \\
Pathological & Neurology & & & \\
Neonatology (PN) & PN - Intensive Care Unit & 10 & $81.2(16.4)$ & $65.0(22.4)$ \\
& PN - Regular Unit & 17 & $76.1(15.4)$ & $76.3(7.6)$ \\
Surgery & Surgery - Boys & 7 & $71.7(18.5)$ & $81.8(14.8)$ \\
& Surgery - Girls & 9 & $84.9(8.5)$ & $87.6(23.5)$ \\
Whole sample & Surgery - Infants & 8 & $70.4(9.4)$ & $73.0(22.7)$ \\
& & 109 & $80.0(15.2)$ & $82.3(16.6)$ \\
\hline
\end{tabular}


Table 2 Correlation matrix between supervisor-rated subjective performance evaluation of decision-making quality (SPEDM), self-rated SPEDM, decision-making styles, and possible covariates in hospital nurses

\begin{tabular}{|c|c|c|c|c|c|c|c|c|c|c|c|c|c|}
\hline & & Mean & $S D$ & 1 & 2 & 3 & 4 & 5 & 6 & 7 & 8 & 9 & 10 \\
\hline 1 & $\begin{array}{l}\text { Self-rated SPEDM } \\
(0-100)\end{array}$ & 80.0 & 15.2 & - & & & & & & & & & \\
\hline 2 & $\begin{array}{l}\text { Supervisor-rated SPEDM } \\
(0-100)\end{array}$ & 82.3 & 16.6 & $\begin{array}{l}.29 \\
* *\end{array}$ & - & & & & & & & & \\
\hline 3 & $\begin{array}{l}\text { Vigilance } \\
(0-12)\end{array}$ & 9.8 & 1.8 & $\begin{array}{c}.20 \\
*\end{array}$ & .15 & $(.61)$ & & & & & & & \\
\hline 4 & $\begin{array}{l}\text { Hypervigilance } \\
(0-10)\end{array}$ & 3.8 & 1.9 & $\begin{array}{c}-.24 \\
*\end{array}$ & -.10 & .17 & $(.66)$ & & & & & & \\
\hline 5 & $\begin{array}{l}\text { Buck-passing } \\
(0-12)\end{array}$ & 4.2 & 2.3 & $\begin{array}{r}-.27 \\
* *\end{array}$ & -.08 & .03 & $\begin{array}{l}.51 \\
* * *\end{array}$ & $(.72)$ & & & & & \\
\hline 6 & $\begin{array}{l}\text { Procrastination } \\
(0-10)\end{array}$ & 2.4 & 2.1 & $\begin{array}{c}-.25 \\
*\end{array}$ & -.14 & -.01 & $\begin{array}{l}.63 \\
* * *\end{array}$ & $\begin{array}{l}.54 \\
* * *\end{array}$ & $(.77)$ & & & & \\
\hline 7 & $\begin{array}{l}\text { Neuroticism } \\
(8-32)\end{array}$ & 20.7 & 5.6 & $\begin{array}{r}-.31 \\
* *\end{array}$ & -.10 & -.02 & $\begin{array}{l}.49 \\
* * *\end{array}$ & $\begin{array}{l}.41 \\
* * *\end{array}$ & $\begin{array}{l}.42 \\
* * *\end{array}$ & $(.80)$ & & & \\
\hline 8 & $\begin{array}{l}\text { Self-esteem } \\
(10-40)\end{array}$ & 31.7 & 4.6 & $\begin{array}{r}.49 \\
* * *\end{array}$ & .08 & .07 & $\begin{array}{l}-.38 \\
* * *\end{array}$ & $\begin{array}{l}-.46 \\
* * *\end{array}$ & $\begin{array}{l}-.38 \\
* * *\end{array}$ & $\begin{array}{l}-.43 \\
* * *\end{array}$ & (.84) & & \\
\hline 9 & $\begin{array}{l}\text { Social Desirability } \\
(0-10)\end{array}$ & 5.7 & 2.0 & .20 & .02 & $\begin{array}{l}.19 \\
*\end{array}$ & $\begin{array}{r}-.26 \\
* *\end{array}$ & $\begin{array}{c}-.18 \\
\dagger\end{array}$ & $\begin{array}{l}-.42 \\
* * *\end{array}$ & $\begin{array}{l}-.45 \\
* * *\end{array}$ & $\begin{array}{l}.26 \\
* *\end{array}$ & $(.60)$ & \\
\hline 10 & $\begin{array}{l}\text { Length of Practice } \\
\text { at the Current Dpt. }\end{array}$ & 10.3 & 7.2 & $\begin{array}{l}.24 \\
*\end{array}$ & $\begin{array}{l}.38 \\
* * *\end{array}$ & .12 & .08 & .10 & .15 & .06 & -.02 & -.09 & - \\
\hline
\end{tabular}

associations between DM styles and supervisor-rated SPEDM. A relatively modest but consistent decrease was found regarding the strength of associations between DM styles and self-rated SPEDM after social desirability was controlled for: in comparison to the data presented in Table 2, the values of standardized Betas fell to $\beta(105)=.17, p<.10$ for vigilance; $\beta(105)=-.20, p<.05$ for hypervigilance; $\beta(105)=-.24, p<.05$ for buck passing; and to $\beta(105)=.20, p<.10$ for procrastination. The total percentage of the variance explained changed only marginally after adding social desirability to the models (data not presented in any table).

\section{Regression Models: Self-Ratings}

The assumption of normality of residuals distribution was violated, thus robust regression methods were used. For the fixed effect multiple regression, the bisquare MM-estimator in the R package robustbase (Maechler et al., 2016) was used. Multilevel (mixed effect) models were calculated using the package robustlmm (Koller, 2016). In the first step of the analysis, the four 
MDMQ subscales were included as predictors (Table 3 ). The only statistically significant predictor of self-rated SPEDM was vigilance. The model explained about $18 \%$ of the variance in self-rated SPEDM.

In the second step, the control variables were added to the model. This improved the model substantially $\left(R^{2}=.33\right)$. However, the effect of vigilance almost disappeared, being statistically significant at the .1 level only. Apart from that, the only statistically significant predictors were self-esteem and length of practice at the current department (Table 3).

No grouping effect by department was observed in regards to associations of the independent variables with self-rated SPEDM. When department was included as a random factor, using the smoothed Huber $\Psi$-function for weighting, the parameter estimates were mostly very similar to those obtained for fixed effect only. Therefore, we do not report them.

\section{Regression Models: Supervisor Ratings}

In the fixed effect multiple regression model, the four MDMQ subscales were included as predictors in Step 1. None of the predictors were significantly related to supervisor-rated SPEDM. The amount of variance in the supervisor ratings explained by the model was low, $R^{2}=.02$, and the value of adjusted $\mathrm{R}^{2}$ was actually negative, $R^{2}=-.01$. Adding the remaining independent variables as a block in Step 2 improved the model substantially (27\%). However, the only statistically significant predictor was practice at the current department, $(\beta(105)=.42, p<.001 ;$ data not presented in any table).

Table 3 Hierarchical regression analyses: Self-rated and supervisor-rated subjective performance evaluation of decision-making quality (SPEDM) in hospital nurses, and their associations with decision-making styles, affective traits, social desirability, and length of practice

\begin{tabular}{|c|c|c|c|c|}
\hline \multirow[t]{2}{*}{ Variable } & \multicolumn{2}{|c|}{$\begin{array}{l}\text { Self-rated SPEDM } \\
\text { (fixed effects only) }\end{array}$} & \multicolumn{2}{|c|}{$\begin{array}{c}\text { Supervisor-rated SPEDM } \\
\text { (fixed effects and } \\
\text { department as a random effect) }\end{array}$} \\
\hline & $\beta 1$ & $\beta 2$ & $\beta 1$ & $\beta 2$ \\
\hline Step 1 & & & & \\
\hline Vigilance & $.28 * *$ & $.18 \dagger$ & .13 & .08 \\
\hline Hypervigilance & -.18 & -.03 & -.09 & -.08 \\
\hline Buck-passing & -.17 & -.06 & -.01 & -.05 \\
\hline Procrastination & -.05 & -.02 & .02 & .00 \\
\hline Step 2 & & & & \\
\hline Neuroticism & & -.09 & & -.02 \\
\hline Self-esteem & & $.33 * *$ & & -.05 \\
\hline Social Desirability & & .04 & & -.05 \\
\hline $\begin{array}{l}\text { Length of Practice } \\
\text { at the Current Dpt. }\end{array}$ & & $.24 * *$ & & $.33 * * *$ \\
\hline Model $\mathrm{R}^{2}$ & .18 & .33 & -.01 & .22 \\
\hline$\Delta \mathrm{R}^{2}$ & & .15 & & .23 \\
\hline
\end{tabular}


The analysis described above did not take into account the grouping of observations. Therefore, we also ran alternative analyses that included the membership at the particular department as a random factor ( $\mathrm{R}$ package robustlmm, using the smoothed Huber $\Psi$-function for weighting). The MDMQ subscales did not add any meaningful information to the model. The only reasonable predictor was the length of practice at the department. Almost 30\% of the variance of supervisor-rated SPEDM was explained by the grouping effect: the intra-class correlations in Step 1 and Step 2 were .28 and .30 , respectively. Due to the strong grouping effect, we found it more suitable to present the results of this mixed effect model rather the one with fixed effects only. Otherwise, their results in regards to the associations between supervisor-rated SPEDM and the predictors were largely similar: again, the only statistically significant predictor of supervisor-rated SPEDM was the length of practice at the department, $\beta(105)=.33, p<.001$ (Table 3).

Due to substantial differences in average scores by nurse managers in each department, we also calculated the regression models with all variables transformed into $z$-scores standardized in each department. These calclulations yielded very similar results to those described above. In all variables, Pearson's correlation coefficients between the standardized and the non-standardized measures were .90 or higher, except for supervisor-rated SPEDM, $r(105)=.84$.

\section{Discussion}

Ad RQ \#1: Is there any relationship between self-reported DM styles of nurses and their SPEDM?

The overall variance in any indicator of SPEDM explained by DM styles was modest (in self-rated SPEDM) or non-existent (in supervisor-rated SPEDM). Self-rated SPEDM was weakly positively related to vigilance and weakly negatively associated with hypervigilance, buck-passing and procrastination. These zero-order correlations of self-rated SPEDM with maladaptive DM styles were weaker than its correlation with neuroticism. Supervisorrated SPEDM was positively associated with vigilance, and negatively to maladaptive DM styles, but none of these relationships were statistically significant.

Previous research regarding MDMQ validation by measuring performance brought inconclusive results, as did our study, which relied on self- and supervisor-ratings of SPEDM. The negative relationship between self-rated decisional procrastination and a non-self-rated measure of performance (Mann et al., 1989) was not confirmed. And while Phillips and Reddie (2007) found no relationship between DM styles and maladaptive behavior at the workplace (selfassessed personal e-mail usage), we did find a negative association of hypervigilance and buck-passing with self-rated SPEDM.

Ad RQ \#2: Does social desirability affect the relationship between DM styles and SPEDM?

Social desirability did not substantially affect any of the associations between DM styles and supervisor-rated SPEDM, with most partials being within 0.02 of the zero orders. This is consistent with the findings of previous studies in organizational and personality research (Moorman \& Podsakoff, 1992; Ones et al., 1996) that, likewise, mostly did not find any inflating or attenuating effect of social desirability on the relationships explored. Nevertheless, the considerable negative correlations between social desirability and self-reported maladaptive DM styles (particularly procrastination) imply that self-enhancement bias in self-reporting DM styles cannot be ruled out. Furthermore, controlling for social desirability did dillute the association between procrastination and self-reported SPEDM, a decrease from $\beta(105)=$ .25 to $\beta(105)=.20$, which suggests that at least part of their shared variance might have oc- 
curred due to self-enhancement or responding to the questions in a socially desirable manner.

Ad RQ \#3: Can DM styles predict SPEDM beyond the other, well-established, personality measures that are related to the conflict theory approach (i.e., neuroticism and self-esteem), and beyond situational variables (i.e., age and length of practice)?

Out of all the potential predictors explored, self-ratings were best predicted by self-esteem. In regards to supervisor-ratings, the strongest predictor by far was the length of practice at the department. In the final multivariate model, the (non-significant) relationships of self-rated SPEDM with DM styles were of about the same - negligible - size as with neuroticism, and much weaker than with self-esteem.

The predictive potential of the MDMQ appears to be very limited, compared to self-esteem (in regards to self-rated SPEDM) or length of practice at the department (in regards to supervisor-rated SPEDM). In explaining the variance of DM quality, DM styles offered very little that was unique. This may sound surprising, since DM styles are a concept that is more specific in regards to DM process than the more general personality constructs of neuroticism or self-esteem. But the absence of the relationship between neuroticism and supervisor-rated SPEDM also seems to contradict the conflict theory. According to its authors, "stress engendered by decisional conflict is a major determinant of failure to achieve high-quality decision-making" (Janis \& Mann, 1977 in Mann et al., 1997). We did not directly measure perceived stress at work. However, previous research indicates that individuals with high neuroticism perceive their events as more stressful and are more emotionally reactive (Gunthert et al., 1999). Despite this, neuroticism did not affect supervisor-rated SPEDM. This finding is also striking when compared to the study by Smith et al. (2001), according to which nurses with high state and trait anxiety were at a higher risk for making medical errors. It cannot be ruled out that a deleterious effect of neuroticism on SPEDM exists, but, for some reason was not detected by our measure of SPEDM. This problem deserves further research.

The strong association of self-esteem with self-rated SPEDM might indicate that confidence enables persons with high self-esteem to make better decisions. However, the correlation also might have occured due to a considerable conceptual/measurement overlap between our measures of self-esteem (RSES scale) and self-rated SPEDM (e.g., the RSES item "I am able to do things as well as most other people"). Also, higher self-esteem people are more apt to self-enhance (Brockner, Wiesenfeld, \& Raskas, 1993), but note that social desirability did not affect the relationship between self-esteem and self-rated SPEDM in our analysis. However, it is possible that individuals with higher self-esteem genuinely perceive themselves as better decision-makers, regardless of the actual qualities of their DM. The extent to which adding self-esteem into the model decreased the associations of self-rated SPEDM with neuroticism and maladaptive DM styles also points to the presence of a common denominator behind all of these constructs - perhaps a global self-image, or negative affectivity.

Ad RQ \#4: Are the relationships explored in research questions 1-3 different for self-rated and supervisor-rated SPEDM?

Relatively little mutual similarity was found between self-rated and supervisor-rated SPEDM. The two indicators of SPEDM also yielded quite different patterns of associations with the potential predictors. When the SPEDM ratings came from the same source as the selfreported DM styles, i.e., from the nurses themselves, individuals who reported applying maladaptive DM styles also tended to report worse DM quality at work. This may indicate that using maladaptive coping patterns in DM leads to impaired DM quality. However, the responses 
in both DM styles and self-rated SPEDM might also reflect global self-image, which manifests itself in a consistent self-reporting of using maladaptive DM styles, along with perceiving oneself as a worse decision maker. These two explanations are not necessarily entirely mutually exclusive.

If the associations between the explanatory variables and self-rated SPEDM are due to global self-image, the image is obviously not shared by their supervisors very regularly. Supervisor-rated SPEDM was clearly associated with the length of practice but showed little to no similarity to self-rated DM styles, or any other personal characteristic. It remains unclear to what extent these results represent reality. Perhaps, indeed, only the lenght of practice matters in DM quality, at least in the explored professional and cultural context. An alternative explanation could be that the raters applied some kind of heuristics, according to which the more experienced nurses should also be better decision makers, regardless of their personalities or coping styles. In any case, the different strength of the associations depending on the source of the ratings corresponds with the findings of Andersen et al. (2016) (albeit from an educational setting unrelated to healthcare), who also reported that the associations were systematically stronger when the performance measure came from the same data source as the explanatory variables.

The lack of similarity between self-ratings and supervisor-ratings is largely consistent with previous research, where only a low to moderate convergence (at best) in ratings was also reported across sources (Conway \& Huffcutt, 1997) as well as a stronger association of many self-rated personality characteristics with selfrated performance rather than with externally rated performance (Wood \& Highhouse, 2014).

These findings do not necessarily imply that relationships between self-reported variables are always upwardly biased, nor that external ratings are a superior, more reliable source of information compared to self-ratings (Conway \& Lance, 2010; Lance, Hoffman, Gentry, \& Baranik, 2008). Proponents of the normative accuracy perspective consider rater source effects as contaminating, performance-irrelevant rater biases (Viswesvaran, Schmidt, \& Ones, 2005). Conversely, Lance et al. (2008) argue from an ecological perspective that "rater source effects do not represent (mere) rater biases but rather represent alternative but complementary valid perspectives on ratee performance" (p. 227). Multiple studies support their view by detecting strong relationships between rater source factors and performance-based external variables (Lance, Baxter, \& Mahan, 2006; Hoffman \& Woehr, 2009; Lance, Teachout, \& Donnelly, 1992). Thus, ratings from different sources can be considered as rather valid measures of performance, even though their applicability across different conditions certainly deserves further study.

\section{Strengths and Limitations}

This study is, to our knowledge, the first attempt to compare all four sub-scales of the MDMQ to an external criterion of DM. Our measure of SPEDM was partly contextualized and measured in a specific profession. The predictive ability of the MDMQ was also compared to other related established psychological constructs, and several situational variables could be controlled for. Another strength of our study is the excellent response rate. Nevertheless, the study has several limitations that need to be considered when interpreting the results.

The Cronbach's Alpha reliability coefficient was relatively low in vigilance (0.60), hypervigilance (0.66) and the SDS X1 scale for social desirability (0.61). In the latter, internal consistency of that size is similar to that found elsewhere, including the original cross-validation study of the scale (Strahan \& Gerbasi, 1972) and is con- 
sidered sufficient for this particular instrument (Haghighat, 2007).

Both in self-ratings and supervisor-ratings, SPEDM was measured only by a single item. The outcome criteria of perceived DM quality might be too global and the variance too low to detect the potentially existing relationships. Also, it can be more susceptible to subjective evaluation, in comparison with assessment of particular, better operationalized outcomes. The wording of the question used for measurement of self-rated SPEDM could also be related to DM confidence, raising questions about the extent of conceptual and measurement overlap with some of the explored constructs. Moreover, supervisor-rated SPEDM may not necessarilly reflect only actual DM performance of the nurses, but also overall assessment of their performance, personal sympathies of the supervisors, or the degree of the nurses' compliance, or personal loyality toward the raters (whose overall number was limited to only 8).

\section{Conclusion and Suggestions for Further Research}

Our findings cast some doubt on the predictive validity of the MDMQ in regard to professional SPEDM. However, more evidence is required for a conclusive verdict. We recommend performing similar research in other professional and cultural contexts, on a bigger sample, including the number of raters. We also recommend the development or use of more elaborate measures of SPEDM, with multiple items exploring different aspects of DM, and with a clearer distinction of measuring DM outcomes or the quality of the DM process. It would also be very helpful to include task-performance measures of DM quality, with high induced stress (that could be measured by physiological correlates as well, see Thunholm, 2008). This could increase the ecological validity of the research, and, at the same time, reflect more appropriately the conflict theory approach upon which the MDMQ is based.

\section{References}

Andersen, L. B., Heinesen, E., \& Pedersen, L. H. (2016). Individual performance: From common source bias to institutionalized assessment. Journal of Public Administration Research and Theory, 26(1), 63-78.

Babak, N. (2015). usdm: Uncertainty Analysis for Species Distribution Models. $R$ package version 1.1-15. Retrieved from https://CRAN.R-project.org/package $=$ usdm

Body of laws of the Slovak Republic (2015a). Vyhláška 364/2005 Z.z., Čiastka 155. http://www.zbierka.sk/ sk/predpisy/364-2005-z-z.p-8773.pdf - Accessed October 20, 2015.

Body of laws of the Slovak Republic (2015b). Predpis č. 296/2010 Z. z. Nariadenie vlády Slovenskej republiky o odbornej spôsobilosti na výkon zdravotníckeho povolania, spôsobe d’alšieho vzdelávania zdravotníckych pracovníkov, sústave špecializačných odborov a sústave certifikovaných pracovných činností. http://www.zakonypreludi.sk/zz/2010-296 - Accessed October 20, 2015.

Bouckenooghe, D., Vanderheyden, K., Mestdagh, S., \& van Laethem, S. (2007). Cognitive motivation correlates of coping style in decisional conflict. The Journal of Psychology, 141(6), 605-626. http:// doi.org/10.3200/JRLP.141.6.605-626

Brockner, J., Wiesenfeld, B. M., \& Raskas, D. F. (1993). Self-esteem and expectancy-value discrepancy: The effects of believing that you can (or can't) get what you want. In Self esteem: The puzzle of low self regard. Plenum series in social/clinical psychology (pp. 219-240).

Chen, P. Y., Dai, T., Spector, P. E., \& Jex, S. M. (1997). Relation between negative affectivity and positive affectivity: Effects of judged desirability of scale items and respondents' social desirability. Journal of Personality Assessment, 69(1), 183-198. http:// doi.org/10.1207/s15327752jpa6901

Conway, J., \& Lance, C. (2010). What reviewers should expect from authors regarding common method bias in organizational research. Journal of Business and Psychology, 25(3), 325-334. http://doi.org/http:// dx.doi.org/10.1007/s1 0869-010-9181-6

Conway, J. M., \& Huffcutt, A. I. (1997). Psychometric properties of multisource performance ratings: A meta-analysis of subordinate, supervisor, peer, and self-ratings. Human Performance, 10(4), 331-360. http://doi.org/10.1207/s15327043hup1004_2 
Crowne, D., \& Marlowe, D. (1960). A new scale of social desirability independent of psychopathology. Journal of Consulting Psychology, 24(4), 349-354. http://doi.org/10.1037/h0047358

Deniz, E. (2011). An investigation of decision making styles and the Five-Factor personality traits with respect to attachment styles. Educational Sciences: Theory \& Practice, 11(1), 105-113.

Dewberry, C., Juanchich, M., \& Narendran, S. (2013). Decision-making competence in everyday life: The roles of general cognitive styles, decision-making styles and personality. Personality and Individual Differences, 55(7), 783-788. http://doi.org/10.1016/ j.paid.2013.06.012

Di Fabio, A. (2006). Decisional procrastination correlates: Personality traits, self-esteem or perception of cognitive failure? International Journal for Educational and Vocational Guidance, 6(2), 109-122. http://doi.org/10.1007/s10775-006-9000-9

Di Fabio, A., \& Palazzeschi, L. (2012). Incremental variance of the core self-evaluation construct compared to fluid intelligence and personality traits in aspects of decision-making. Personality and Individual Differences, 53(3), 196-201. http://doi.org/ $10.1016 /$ j.paid 2012.03 .012

Effert, B. R., \& Ferrari, J. R. (1989). Decisional procrastination: Examining personality correlates. Journal of Social Behavior \& Personality, 4(1), 151161. Retrieved from http://ezproxy.umuc.edu/ login? url=http://search.ebscohost.com/ login.aspx?direct $=$ true $\& d b=$ psyh $\& A N=1989$ 36466-001\&site $=$ eds-live $\&$ scope $=$ site

Engkvist, D. (2010). Beslutsfattandesstilar hos svenska officerskadetter (thesis). Retrieved from http:// lup.lub.lu.se

Ferrari, J. R. (1994). Dysfunctional procrastination and its relationship with self-esteem, interpersonal dependency, and self-defeating behaviors. Personality and Individual Differences, 17(5), 673-679. http:/ /doi.org/10.1016/0191-8869(94)90140-6

Ganster, D. C., Hennessey, H. W., \& Luthans, F. (1983). Social desirability response effects: Three alternative models. Academy of Management Journal, 26(2), 321-331. http://doi.org/10.2307/255979

Gorodetzky, H., Sahakian, B. J., Robbins, T. W., \& Ersche, K. D. (2011). Differences in self-reported decision-making styles in stimulant-dependent and opiate-dependent individuals. Psychiatry Research, 186(2-3), 437-440. http://doi.org/http://dx.doi.org/ 10.1016/j.psychres.2010.07.024

Gunthert, K. C., Cohen, L. H., \& Armeli, S. (1999). The role of neuroticism in daily stress and coping. Journal of Personality and Social Psychology, 77(5), 1087-1100. http://doi.org/10.1037/0022-3514.77.5. 1087
Haghighat, R. (2007). The development of the Brief Social Desirability Scale (BSDS). Europe's Journal of Psychology, 3(4). http://doi.org/10.5964/ejop. v3i4.417

Halama, P., \& Gurňáková, J. (2014). Need for structure and Big Five personality traits as predictors of decision making styles in health professionals. Studia Psychologica, 56(3), 171-179. Retrieved from http:/ /search.ebscohost.com/login.aspx?direct=true\& $\mathrm{db}=$ psyh\& $\mathrm{AN}=2014-52723-002 \&$ site=ehost livelnpeter.halama@savba.sk

Hoffman, B. J., \& Woehr, D. J. (2009). Disentangling the meaning of multisource performance rating source and dimension factors. Personnel Psychology, 62, 735-765. http://doi.org/10.1111/j.1744$6570.2009 .01156 . x$

Hoffman, C. C., Nathan, B. R., \& Holden, L. M. (1991). A comparison of validation criteria: Objective versus subjective performance measures and self- versus supervisor ratings. Personnel Psychology, 44, 601 618. http://doi.org/10.1111/j.1744-6570.1991. tb02405.x

John, O. P., Naumann, L. P., \& Soto, C. J. (2008). Paradigm shift to the integrative Big-Five trait taxonomy: History, measurement, and conceptual issues. In Handbook of personality: Theory and research (pp. 114-158).

Kamhalová, I., Halama, P., \& Gurňáková, J. (2013). Affect regulation and decision making in healthcare professionals: Typology approach. Studia Psychologica, 55(1), 19-31. Retrieved from http:// search.ebscohost.com $/ \log$ in.aspx? direct $=$ true $\&$ $\mathrm{db}=$ psyh\&AN=2013-14002-002\&site=ehost live\nivana.kamhalova@savba.sk

King, M. F., \& Bruner, G. C. (2000). Social desirability bias: A neglected aspect of validity testing. Psychology and Marketing, 17(2), 79-103. http://doi.org/ 10.1002/(SICI)1520-6793(200002)17:2<79::AIDMAR2>3.0.CO;2-0

Koller, M. (2016). robustlmm: An R package for robust estimation of linear mixed-effects models. Journal of Statistical Software, 75(6), 1-24. http://doi.org/ 10.18637/jss.v075.i06

Lance, C. E., Baxter, D., \& Mahan, R. P. (2006). Multisource performance measurement: A reconceptualization. In W. Bennett, C. E. Lance, \& D. J. Woehr (Eds.), Performance measurement: Current perspectives and future challenges (pp. 49-76). Mahwah, NJ: Erlbaum.

Lance, C. E., Hoffman, B. J., Gentry, W. A., \& Baranik, L. E. (2008). Rater source factors represent important subcomponents of the criterion construct space, not rater bias. Human Resource Management Review, 18(4), 223-232. http://doi.org/10.1016/j.hrmr. 2008.03 .002 
Lance, C. E., Teachout, M. S., \& Donnelly, T. M. (1992). Specification of the criterion construct space: An application of hierarchical confirmatory factor analysis. Journal of Applied Psychology, 77(4), $437-$ 452. http://doi.org/10.1037//0021-9010.77.4.437

Leary, M. R., \& Downs, D. L. (1995). Interpersonal functions of the self-esteem motive: The self-esteem system as a sociometer. In Efficacy, agency, and self-esteem (pp. 123-144). http://doi.org/ 10.1007/978-1-4899-1280-0 7

Leykin, Y., \& DeRubeis, R. J. (2010). Decision-making styles and depressive symptomatology: Development of the Decision Styles Questionnaire. Judgment and Decision Making, 5(7), 506-515.

Loewenstein, G., \& Lerner, J. S. (2003). The role of affect in decision making. Handbook of Affective Science. http://doi.org/10.1016/B978-0-444-626042.00003-4

Maechler, M., Rousseeuw, P., Croux, C., Todorov, V., Ruckstuhl, A., Salibian-Barrera, M., Verbeke, T., Koller, M., Conceicao, E. L. T., \& di Palma, M. A. (2016). robustbase: Basic Robust Statistics $R$ package version 0.92-7. Retrieved from http:/CRAN.Rproject.org/package $=$ robustbase

Mann, L., Beswick, G., Allouache, P., \& Ivey, M. (1989). Decision workshops for the improvement of decision-making skills and confidence. Journal of Counseling \& Development, 67(8), 478. Retrieved from http://search.ebscohost.com/login.aspx?direct= true $\& \mathrm{db}=$ bth $\& A N=4966288 \&$ site $=$ ehost-live

Mann, L., Burnett, P., Radford, M., \& Ford, S. (1997). The Melbourne Decision Making Questionnaire: An instrument for measuring patterns for coping with decisional conflict. Journal of Behavioral Decision Making, 10(1), 1-19. http://doi.org/10.1002/ (SICI) 1099-0771(199703)10:13.0.CO;2-X

Moorman, R. H., \& Podsakoff, P. (1992). A metaanalytic review and empirical test of the potential confounding effects of social desirability response sets in organizational behavior research. Journal of Occupational and Organizational Psychology, 65, 131-150.

Nathan, B. R., \& Alexander, R. A. (1988). A comparison of criteria for test validation: A meta-analytic investigation. Personnel Psychology, 41(3), $517-$ 535. http://doi.org/10.1111/j.1744-6570.1988. tb00642.x

Ones, D. S., Viswesvaran, C., \& Reiss, A. D. (1996). Role of social desirability in personality testing for personnel selection: The red herring. Journal of
Applied Psychology, 81(6), 660-679. http://doi.org/ 10.1037/0021-9010.81.6.660

Phillips, J. G., \& Reddie, L. (2007). Decisional style and self-reported Email use in the workplace. Computers in Human Behavior, 23(5), 2414-2428. http:/ /doi.org/10.1016/j.chb.2006.03.016

Rosenberg, M. (1965). Rosenberg Self-Esteem Scale. New York, http://doi.org//S0034-988720090006 00009

Scott, S. G., \& Bruce, R. A. (1995). Decision-making style: The development and assessment of a new measure. Educational and Psychological Measurement, 55(5), 818-831. http://doi.org/10.1177/ 0013164495055005017

Spector, P. E. (2006). Method variance in organizational research: Truth or urban legend? Organizational Research Methods, 9(2), 221-232. http:// doi.org/10.1177/1094428105284955

Smith, A. M., Ortiguera, S. A., Laskowski, E. R., Hartman, A. D., Mullenbach, D. M., Gaines, K. A., ... \& Fisher, W. (2001). A preliminary analysis of psychophysiological variables and nursing performance in situations of increasing criticality. Mayo Clinic Proceedings, 76(3), 275-284. http://doi.org/ $10.4065 / 76.3 .275$

Strahan, R., \& Gerbasi, K. C. (1972). Short, homogeneous versions of the Marlowe-Crowne Social Desirability Scale. Journal of Clinical Psychology, 28(2), 191-193.

Thompson, C. (2004). Nurses, information use, and clinical decision making - the real world potential for evidence-based decisions in nursing. EvidenceBased Nursing, 7(3), 68-72. http://doi.org/10.1136/ ebn.7.3.68

Thunholm, P. (2008). Decision-making styles and physiological correlates of negative stress: Is there a relation?: Cognition and Neurosciences. Scandinavian Journal of Psychology, 49(1995), 213-219. http://doi.org/10.1111/j.1467-9450.2008.00640.x

Viswesvaran, C., Schmidt, F. L., \& Ones, D. S. (2005). Is there a general factor in ratings of job performance? A meta-analytic framework for disentangling substantive and error influences. Journal of Applied Psychology, 90(1), 108-131. http://doi.org/ 10.1037/0021-9010.90.1.108

Wood, N. L., \& Highhouse, S. (2014). Do self-reported decision styles relate with others' impressions of decision quality? Personality and Individual Differences, 70, 224-228. http://doi.org/10.1016/j.paid. 2014.06 .036 